\title{
Noxious Weed Seed Deactivation by Thermophilic Anaerobic Digestion, and the Effects on Fungal Growth.
}

\author{
Patrick J. O’Dell, M.Sc. ${ }^{1}$, Cesar M Moreira, Ph.D. ${ }^{1},{ }^{2}$, and Pratap Pullammanappillil, Ph. D. ${ }^{1}$ \\ ${ }^{1}$ ABE - Agricultural and Biological Engineering Department, University of Florida, Gainesville, FL 32611, USA, \\ pcpratap@ufl.edu \\ ${ }^{2}$ ESPOL Escuela Superior Politécnica del Litoral, Facultad de Ingeniería Mecánica y Ciencias de la Producción, \\ Campus Gustavo Galindo, Km 30.5 Vía Perimetral, P.O. Box 09-01-5863 Guayaquil, ECUADOR, \\ cemoreir@espol.edu.ec
}

\begin{abstract}
There are numerous benefits of using anaerobic digestion to treat organic wastes. Anaerobic digestion to treat sugar beet scrap materials has been proven as an effective alternative to landfilling. Byproducts of the anaerobic digestion process are liquid effluent and volume-reduced sludge. It is proposed that liquid effluent and sludge can be placed on arable lands. In order to return these byproducts, noxious weed seeds that may enter the digestion process must be eradicated in the process. This study was undertaken to determine if five species of noxious weeds seeds would be destroyed by anaerobic digestion. Small batch anaerobic digesters were made to study its effect on five weed species. The digestion lasted for 10 days and was performed at 55 ${ }^{\circ} \mathrm{C}$. Five additional samples were used to determine the effects of warm water on the seeds. In addition, five dry containers with dry seeds were incubated to determine the effects of dry heat. Results showed that both anaerobic digestion leachate and warm water caused seed destruction for the all seeds compared to dry heat treatment or no treatment. A secondary observation showed that fungal growth was inhibited by anaerobic digestion.

Keywords-- Anaerobic Digestion, Weed Seeds, Fungus, Thermophilic, Composting.
\end{abstract}

Digital Object Identifier (DOI):

http://dx.doi.org/10.18687/LACCEI2016.1.1.355

ISBN: 978-0-9822896-9-3

ISSN: $2414-6390$

$14^{\text {th }}$ LACCEI International Multi-Conference for Engineering, Education, and Technology: "Engineering Innovations for Global Sustainability", 20-22 July 2016, San José, Costa Rica. 


\title{
Noxious Weed Seed Deactivation by Thermophilic Anaerobic Digestion, and the Effects on Fungal Growth.
}

\author{
Patrick J. O'Dell, M.Sc. ${ }^{1}$, Cesar M Moreira, Ph.D. ${ }^{1,2}$, and Pratap Pullammanappillil, Ph. D. ${ }^{1}$ \\ ${ }^{1}$ ABE - Agricultural and Biological Engineering Department, University of Florida, Gainesville, FL 32611, USA, \\ pcpratap@ufl.edu \\ ${ }^{2}$ ESPOL Escuela Superior Politécnica del Litoral, Facultad de Ingeniería Mecánica y Ciencias de la Producción, Campus \\ Gustavo Galindo, Km 30.5 Vía Perimetral, P.O. Box 09-01-5863 Guayaquil, ECUADOR, cemoreir@espol.edu.ec
}

\begin{abstract}
There are numerous benefits of using anaerobic digestion to treat organic wastes. Anaerobic digestion to treat sugar beet scrap materials has been proven as an effective alternative to landfilling. Byproducts of the anaerobic digestion process are liquid effluent and volume-reduced sludge. It is proposed that liquid effluent and sludge can be placed on arable lands. In order to return these byproducts, noxious weed seeds that may enter the digestion process must be eradicated in the process. This study was undertaken to determine if five species of noxious weeds seeds would be destroyed by anaerobic digestion. Small batch anaerobic digesters were made to study its effect on five weed species. The digestion lasted for 10 days and was performed at $55{ }^{\circ} \mathrm{C}$. Five additional samples were used to determine the effects of warm water on the seeds. In addition, five dry containers with dry seeds were incubated to determine the effects of dry heat. Results showed that both anaerobic digestion leachate and warm water caused seed destruction for the all seeds compared to dry heat treatment or no treatment. A secondary observation showed that fungal growth was inhibited by anaerobic digestion.
\end{abstract}

Keywords-- Anaerobic Digestion, Weed Seeds, Fungus, Thermophilic, Composting.

\section{INTRODUCTION}

There are numerous benefits of using anaerobic digestion to treat organic wastes. Controlled anaerobic digestion is both an effective way to reduce the volume of organic waste and to produce a methane-rich gas commonly known as biogas, which can be converted into heat energy or electricity $[2,3]$. In addition, anaerobic digestion in vessels or covered lagoons is a viable and economical way to manage organic wastes on site in areas where landfill disposal is expensive or not available [4].

The use of anaerobic digestion to treat sugar beet (Beta vulgaris $L$.) tailings, a byproduct of sugar refining, has been proven as an effective alternative to land filling [1]. The anaerobic digestion process produces three main products, a methane-rich gas known commonly as biogas, a liquid effluent, and a volume-reduced portion of digested sludge. Both the liquid effluent and the sludge contain beneficial nutrients including nitrogen, phosphorous, and a variety of minerals $[5,6$, and 7$]$.

It has been proposed that the liquid effluent and the solid sludge from the anaerobic digestion of sugar beet tailings can be placed back on arable sugar beet fields to help fertilize the soil. In order to safely return these two digestion products, it is necessary to ensure that noxious plant seeds that may enter the anaerobic digester with sugar beet tailings are eradicated

Digital Object Identifier (DOI): http://dx.doi.org/10.18687/LACCEI2016.1.1.355 ISBN: 978-0-9822896-9-3

ISSN: 2414-6390 by the anaerobic digestion process. Noxious plants include potential weeds that may be detrimental to the growth of sugar beets. There are hundreds of varieties of noxious weeds and many studies have been undertaken to ensure the destruction of viable weed seeds when organic matter is composted aerobically $[7,8,9,10$, and 11]. Marketable compost is required to have all weeds seeds inactivated [7]. A common practice to ensure the inactivation of noxious weed seeds is to monitor the temperature of the aerobic compost process and ensure that this temperature is held for an extended period of time [9]. However, in experiments looking at the viability of weed seeds through aerobic composting with beef cattle manure, Larney and Blackshaw [10] attempted to find a correlation between temperature and seed viability. Their results instead showed that only 17 to $29 \%$ of the variation in viability could be accounted due to temperature [10]. Thus, temperature is likely not the only factor affecting weed seed inactivation. Research by Ozores - Hampton [11] and OzoresHampton, M., Obreza, T.A., Stofella, P., and Fitzpatrick [12] concluded that weed suppression is more likely due to the physical properties of the composted soil materials and/or the action of phytotoxic compounds that are produced by the microbial populations in the composting process. Weed suppression is expected to be enhanced through a better understanding of soil and natural organic chemicals and soil microbial populations [13].

It has been shown that some seeds are destroyed or deactivated by the anaerobic digestion process $[14,15]$ For example, Ryckeboer, J., Cops, S., and Cooseman, J. [14] determined that the viability of Tomato seeds was destroyed by an anaerobic digestion process of only 1 day at $52^{\circ} \mathrm{C}$.

Due to the relative hardiness and durability of certain noxious weed seeds, this study was undertaken to determine if five species of noxious weeds seeds would be destroyed by an anaerobic digestion processing.

\section{MATERIAL AND METHODS}

\section{A. FEEDSTOCK}

The five weed species selected were provided by the University of Florida Agronomy Department. The sugar beet seeds used for this study were provided by the American Crystal Sugar Company. These seeds were not pretreated with any fungicides or herbicides.

\section{B. SAMPLE PREPARATION}

$14^{\text {th }}$ LACCEI International Multi-Conference for Engineering, Education, and Technology: "Engineering Innovations for Global Sustainability", 20-22 July 2016, San José, Costa Rica. 
Weed seeds. Five different weed samples were used in this experiment. A specific amount of seeds from each one of the five particular weeds species were used, as shown below:

1. 2.0 g. of Common Ragweed seeds (approx. 200 seeds)

2. 4.0 g. of Sicklepod seed (approx. 200 seeds)

3. 1.0 g. of Redroot Pigweed seeds (approx. 400 seeds)

4. 2.0 g. of Pale Smartweed seeds (approx. 300 seeds)

5. $2.5 \mathrm{~g}$. of Wild Mustard seeds (approx. 300 seeds)

These amounts were used because these amounts of seeds covered roughly fifty percent of a standard Petri dish.

Sugar beet tailings. To minimize the possibilities of pickling during the anaerobic digestion a pretreatment wash was performed on the sugar beet tailings. The procedure was, soaking the sugar beet tailings in warm tap water $\left(50^{\circ} \mathrm{C}\right)$ for 20 minutes to remove some of the easily soluble sugars. The initial $\mathrm{pH}$ of the five samples varied between 9 and 9.4. The bottles were sealed with a rubber stopper and aluminum caps in order to ensure anaerobic conditions (Figure 1).

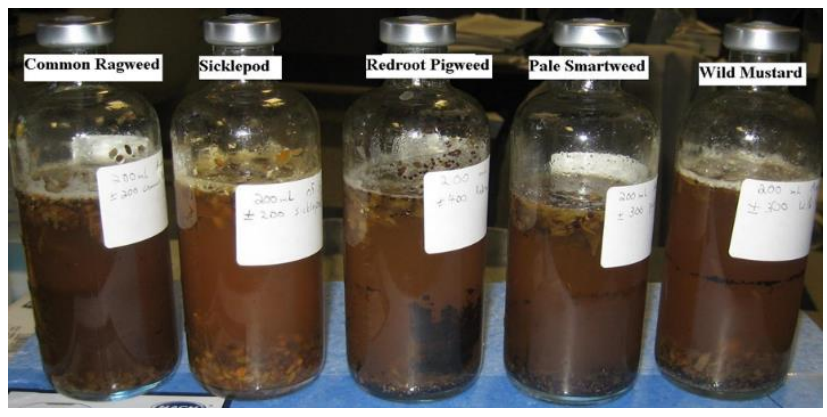

Figure 1- Five samples of noxious weeds with washed sugar beet tailings and anaerobic digestion inoculum leachate.

\section{METHODS OF POTENTIALLY INHIBITING GERMINATION}

Anaerobic digestion. (AD) or biogasification is a biological process in which microorganisms break down organic matter into methane and carbon dioxide under anaerobic (or no oxygen) conditions $[16,17]$. To reach anaerobic digestion 300 $\mathrm{mL}$ air tight bottles were used. Before closing the bottles, 150 $\mathrm{mL}$ of activated leachate containing mixed-culture anaerobic bacteria, $50 \mathrm{~mL}$ of deionized water, $10 \mathrm{~g}$ of washed sugar beet tailings, and a specific amount of seeds from one of the five particular weeds were placed in each bottle. Then the sealed bottles were placed in an incubator set at $55^{\circ} \mathrm{C}$. The anaerobic digestion run for 10 days, and the produced biogas was measured and analyzed for methane content.

Gas chromatography. Samples of biogas were analyzed for methane and carbon dioxide using a Fisher Gas Partitioner Model 1200 equipped with thermal conductivity detector. Details of these analytical procedures have been explained in Polematidis, I. Koppar, A., Pullammanappallil, P., Seaborn, S. [1].
Dry heat. An important factor that can be accountable for the weed seeds to not germinate is temperature. To clear up these possibility petri dishes containing dry seeds of four of the five weed seeds (Ragweed, Sicklepod, Redroot, and Smartweed) and sugar beet seeds were placed into the incubator for 10 days at $55^{\circ} \mathrm{C}$. The Wild Mustard was not used due to its unsuccessful results in the anaerobic digestion. After the 10 days, the five Petri dishes were removed from the incubator, opened and the seeds were removed for germination testing.

Wet heat. Additionally, five $300 \mathrm{~mL}$ bottles were filled with $100 \mathrm{~mL}$ of Deionized water and an amount of seeds from one of the five particular varieties as shown below:

1. 2.0 g. of Common Ragweed seeds (approx. 200 seeds)

2. 4.0 g. of Sicklepod seed (approx. 200 seeds)

3. 1.0 g. of Redroot Pigweed seeds (approx. 400 seeds)

4. 2.0 g. of Pale Smartweed seeds (approx. 300 seeds)

5. 3.5 g. of Sugar Beet seeds (approx. 300 seeds)

After the 10 days, the five bottles were removed from the incubator. The bottles were opened and the seeds were removed for germination testing.

\section{METHOD OF TESTING GERMINATION VIABILITY}

After the 10 day digestion period, the bottles were opened and the seeds were screened and placed in Petri dishes to study its germination. Each Petri dish contained two folded KimWipes ${ }^{\circledR}$, one below the seeds being germinated and one above the seeds. A total of fifteen Petri dishes were used for the germination test. Each of the five varieties of seeds had three types of germination samples, thus equaling fifteen total Petri dish samples. For each of the five varieties, the first type of samples consisted of the digested weed seeds removed from the bottles as well as $3 \mathrm{~mL}$ of the leachate from the respective bottle and $7 \mathrm{~mL}$ of tap water. The second type of samples consisted of dry, undigested seeds that were initially treated with $7 \mathrm{~mL}$ of tap water plus $3 \mathrm{~mL}$ of leachate from the bottle containing that particular seed. The third type of samples consisted of dry, undigested seeds that were treated with 10 $\mathrm{mL}$ of tap water.

These fifteen Petri dish samples were left to germinate in the dark. The samples were observed once a day, and $3 \mathrm{~mL}$ of DI water was added to each sample daily so that the seeds would not dry out.

Initially $10 \mathrm{~mL}$ of tap water was added to each of the seed samples. The samples were left to germinate in the dark, and they were daily observed and wetted with $3 \mathrm{~mL}$ of DI water.

\section{RESULT AND DISCUSSION}

Figure 2 shows the average gas produced from each of the weed samples. There was no noticeable difference in gas production until approximately day 4, at which time the amount produced in the bottle containing mustard seeds showed somewhat less. Most of the biogas was assumed to

$14^{\text {th }}$ LACCEI International Multi-Conference for Engineering, Education, and Technology: "Engineering Innovations for Global Sustainability", 20-22 July 2016, San José, Costa Rica. 
come from the sugar beet tailings and not the actual seeds, however there may have been some inhibiting chemical or organism attributed with the mustard seeds which caused this particular bottle to produce less biogas than the other four. In addition, on the fourth day gas samples were taken from both the Wild Mustard bottle and the Pale Smartweed bottle. The sample biogas from the Wild Mustard had only 27\% methane whereas the sample gas from the Pale Smartweed had approximately $40 \%$. Methane compositions as high as $50 \%$ methane were obtained by day 6 of the digestion, and no readings were available after this date due to a malfunction with the Gas Chromatograph.

It is estimated that washed sugar beet tailings have approximately a $20 \%$ solids, and the solids are approximately $90 \%$ biodegradable [1]. Thus the $10 \mathrm{~g}$. of tailings will contain $1.8 \mathrm{~g}$. of volatile solids (VS). 1 gram VS will produce approximately 270 cubic centimeters (cc) of methane. Since the concentration of biogas is estimated at $50 \%$ methane, this equates to approximately $540 \mathrm{cc}$ Biogas / g. VS or $972 \mathrm{cc}$ Biogas for the 10 grams of washed tailings

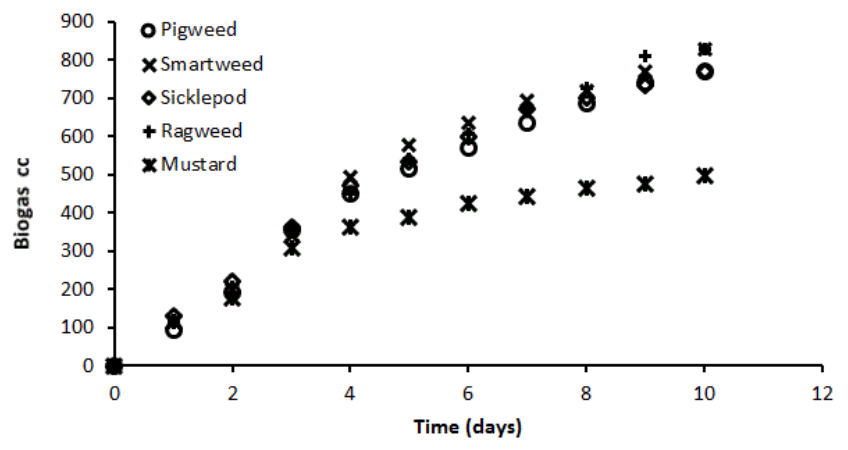

Figure 2- Biogas produced from the five different samples of $10 \mathrm{~g}$ sugar beet tailings and 5 different weed seeds.

From Figure 2, it is apparent that the four weed seeds, Redroot Pigweed, Pale Smartweed, Sicklepod, and Common Ragweed, did not inhibit the anaerobic digestion process or the gas production. However, the Wild Mustard did appear to inhibit the production of biogas.

There were a number of important observations that occurred in some of the seeds studied. First, none of the wild mustard seeds ever appeared to open or germinate. In addition, the wild mustard seeds did not show any signs of macroscopic mold growth as did some of the other seeds studies. Thus, it was concluded that the wild mustard seeds used were not viable for the duration of the experiment.

It was observed during the 10 day digestion period that definitely two and possibly four of the five seed varieties opened and began germination in the bottles. This is not surprising since moisture is usually the main cause for seed germination. Figure 3 shows the red pigweed and pale smartweed seeds exposing the inner white portion of the seed after two days of incubation the bottles.

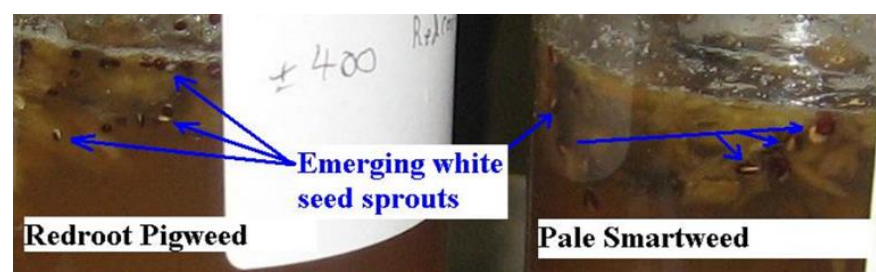

Figure 3- Emerging Sprouts from Redroot Pigweed and Pale Smartweed Samples

Once the seeds open, their protective outer layer goes away and the starch-rich endosperm were subject to anaerobic digestion by the mixed culture of bacteria. After four days of germination, none of the 5 varieties of digested seeds showed any large or growing sprouts. However, the undigested seeds for Common Ragweed, Sicklepod, and Redroot Pigweed, all showed some sprouting seeds. Both the digested and undigested Pale Smartweed seeds opened. No large or noticeable sprouts grew from the opened Smartweed seeds, and other than the digested seeds being slightly darker in color there was very little visual difference between the digested and undigested Smartweed seeds. Thus it was difficult to determine whether or not the digested smartweed seeds were able to germinate into Smartweed plants. Further studies using soil for germination media are recommended for the Pale Smartweed.

There was an explicit difference between the digested seeds, the effluent treated seeds, and the $\mathrm{H}_{2} \mathrm{O}$ treated seeds in terms of fungal growth on the seeds. The most notable fungal growth occurred in the Sicklepod samples and the Common Ragweed Samples. Figures 4 and 5 below show these two varieties after four days of germination.

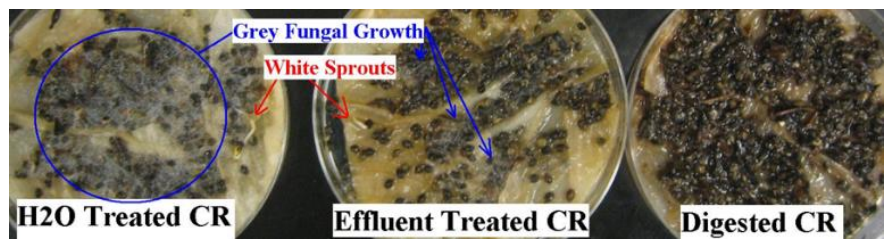

Figure 4- Common Ragweed (CR) Seed Germination Trail

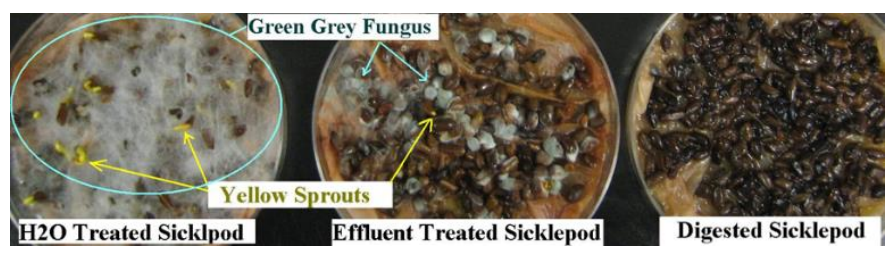

Figure 5- Sicklepod Seed Germination Trial

Notice that major fungal growth occurred on both Common Ragweed and Sicklepod seeds that were treated solely with water, whereas only minor fungus grew on the effluent treated seeds. No fungal growth was observed on the digested Common Ragweed or the Sicklepod. It is also important to note that the fungus growing on the ragweed was visually different than the fungus growing on the Sicklepod, because this implies that fungal species are specific to the seed 
varieties. The anaerobic digestion process appears to have eliminated fungal growth from both seed varieties.

The small amount of fungus on the effluent treated seeds compared to the large amounts of fungus on the water treated seeds could imply one of two things. The fungal growth could be inhibited by the anaerobic digestion effluent, or the fungus did not grow because a higher concentration of nutrients was available to the seeds. The fungus tended to begin growing directly on the seeds, and thus the fungus may have been in a symbiotic relationship with the plant seed by delivering nutrients to the plant seed. However, if sample nutrients were supplied to the seeds by the anaerobic digestion effluent, then the fungus may not have been as necessary for seed germination and growth. Due to the larger and greater number of weed sprouts that grew in the water treated seeds compared to the effluent treated seeds, it is likely that the effluent inhibited both fungal growth and the growth of the weed seeds. This inhibition may be due to volatile fatty acids (VFA), which are known to be produced in the anaerobic digestion process and can inhibit germination and growth of plants $[18,19]$. Since the Petri dishes were regularly covered, these VFA's would not be able to volatilize to the atmosphere or be neutralized by soil microorganisms as would occur in the natural environment.

There was no notable difference between the dry heated seeds and the dry unheated seeds after the heating process. In addition, the sprouting of these two seed types showed no apparent differences. Fungal growth during germination was the same for the dry heated seeds as for the unheated seeds. However, for the wet heated seeds there were some interesting differences. The sugar beet seeds were very important because they had a high germination rate. The number and length of the sprouts from the dry heated and unheated sugar beet samples were almost identical. However, none of the wet heated sugar beet seeds germinated. Some of the weed seeds, including the sicklepod, the pigweed, and the ragweed showed similar results, however it was more difficult to ensure statistically accurate data due to the lower germination rates of these seeds.

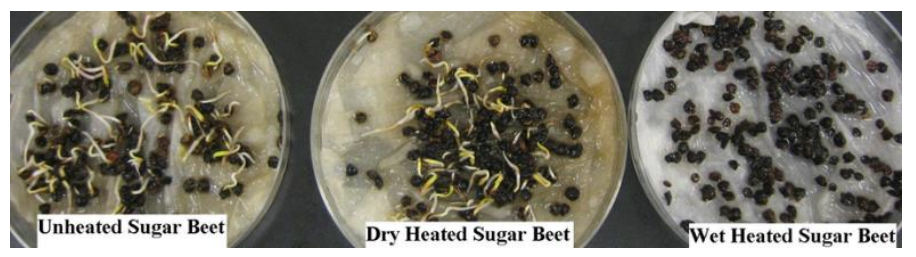

Figure 6- Sugar Beet Seed Germination Trial

Another notable observation was that the wet heat treatment did not eliminate fungal growth on the seeds as did the anaerobic treatment. Wet heated sicklepod seeds showed small amounts of fungal growth after only two days. (Figure 7)

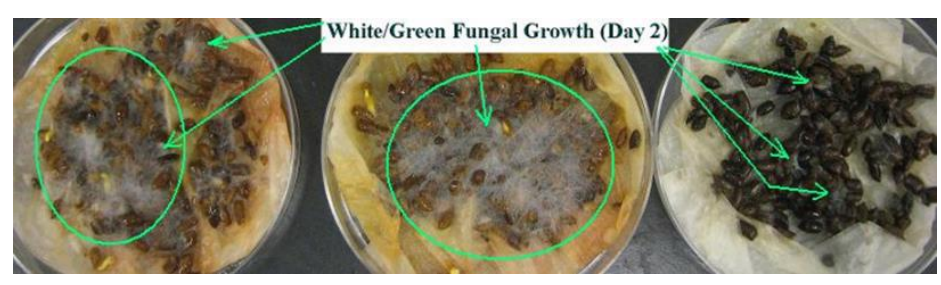

Figure 7: Heated Sicklepod Seed Trials showing Fungal Growth

Table 1 shows seeds with fungal growth. Thus the heat does not completely inhibit fungal growth whereas the anaerobic digestion did appear to completely inhibit fungal growth

TABLE I

FUNGAL GROWTH RESULTS FOR THE SIX SEED VARIETIES STUDIED. "YES" INDICATED FUNGAL GROWTH OBSERVED. "NO" INDICATES NO FUNGAL GROWTH OBSERVED. "HIGH" INDICATES A LARGE AMOUNT OF FUNGAL GROWTH. "LOW" INDICATES A SIGNIFICANTLY LESS FUNGAL GROWTH.

\begin{tabular}{|c|c|c|c|c|c|}
\hline weed & unheated & dry heated & $\begin{array}{c}\text { wet } \\
\text { heated }\end{array}$ & $\begin{array}{c}\text { unheated w/ } \\
\text { efluent }\end{array}$ & AD \\
\hline ragweed & yes-high & yes- high & no & yes- Low & no \\
\hline sicklepod & yes- high & yes- high & yes- low & yes- low & no \\
\hline redroot pigweed & no & no & no & no & no \\
\hline pale smartweed & no & no & no & no & no \\
\hline mustard & n/a & n/a & n/a & n/a & n/a \\
\hline
\end{tabular}

*N/A: NON AVAILABLE DATA, FAILED RUN

\section{CONCLUSION}

More research needs to be done to ensure that anaerobic digestion leachate and biosolids are suitable materials for land application. Nonetheless, it is encouraging that none of the digested weed seeds germinated. In addition, the inhibition of fungal growth on all of the digested weed seeds shows a good indication that sugar beet fungal pathogens may also be inhibited by anaerobic digestion.

Future studies should be performed to determine if certain plant pathogenic fungus can be inactivated or eliminated by anaerobic digestion treatment or if anaerobic digestion leachate has any natural fungicidal properties. In addition, the effect of anaerobic digestion leachate on growing sugar beets from seed also needs to be determined prior to any land application considerations.

This inhibition of fungal growth and seed germination may be due to volatile fatty acids (VFA), which are known to be produced in the anaerobic digestion process and can inhibit germination and growth of plants. Since the Petri dishes were regularly covered, these VFA's would not be able to volatilize to the atmosphere or be neutralized by soil microorganisms as would occur in the natural environment. It would be beneficial to replicate the experiment but allowing some of the Petri dishes to be left uncovered in a biological chamber to allow the volatilization of the any fatty acid molecules that may inhibit either seed germination or fungal growth.

\section{ACKNOWLEDGMENT}


The authors are grateful for the cooperation of the University of Florida Agronomy Department and the the University of Florida Agricultural and Biological Engineering Department for their support.

\section{REFERENCES}

[1] Polematidis, I., Koppar, A., Pullammanappallil, P., Seaborn, S. 2008. Biogasification of sugar beet processing by-products. Zuckerindustrie (Berlin, Germany) 133:5 p. 323 - 329

[2] of Municipal Solid Wastes. Microbiology of Solid Waste. pp. 71-113

[3] Chynoweth, D. P., V. J. Srivastava, M. P. Henry, and P. B. Tarman, 1980. Biothermal gasification of biomass. Energy from Biomass and Wastes IV, 527-554.

[4] Fricke, K., H. Santen, R. Wallman. 2005 "Comparison of selected aerobic and anaerobic procedures for MSW treatment." Waste Management. Volume 25, Issue 8, Pp. 799-810 DOI:10.1016

[5] Wilkie, Ann C. 2000. Anaerobic digestion: Holistic Processing of Animal Manures. P.1-12. in Proceedings of the Animal Residuals Management Conference, Water Environment Federation, Alexandria.

[6] Berglund, $\mathrm{M}$ and Börjesson, P., 2006. Assessment of energy performance in the life - cycle of biogas production. Biomass and Bioenergy 30 (3): 254 - 266

[7] Chynoweth, D. P., P. Haley, J. Owens, E. Rich, A. Teixeira, B. Welt, T. Townsend, and H. Choi. 2002. Anaerobic composting for recovery of nutrients, compost, and energy from solid wastes during space missions. Paper No. 2002-01-2351. In International Conference on Environmental Systems

[8] Braber, K. 1995. Anaerobic Digestion of Municipal Solid Waste: A Modern Waste Disposal Option on the verge of Breakthrough." Biomass and Bioenergy, Vol. 9, Issues 1-5. p. 375

[9] Insam, Klammer, Reddich. 2002. Microbiology of Composting. Springer
Verlag Berlin Heidelberg.

[10] Blackshaw \& Larney. 2003. Weed Seed Viability in Composted Beef Cattle Feedlot Manure. Journal of Environmental Quality. 32:11051113

[11] Stoffella \& Kahn. 2001. Compost Utilization in Horticultural Cropping Systems. CRC Press. pp. 275-276

[12] Ozores-Hampton. 1998. Compost as an alternative Weed Control Method. University of Florida. IFAS. Southwest Florida Research and Education Center.

[13] Monica Ozores-Hampton, Thomas A. Obreza, Peter J. Stoffella, and George Fitzpatrick. 2002. Immature Compost Suppresses Weed Growth under Greenhouse Conditions. Compost Science and Utilization. Vol. 10 (2) 105-113

[14] Buhler, Douglas D. 1999. Expanding the Context of Weed Management. Haworth Press. 95

[15] Ryckeboer, J., S. Cops, and J. Coosemans. 2002 The fate of plant pathogens and seeds during anaerobic digestion and aerobic composting of source separated household wastes. Compost Science \& Utilization. Vol. 10 (3) 204-216

[16] Chynoweth, D. P., P. C. Pullammanappallil, 1996. Anaerobic Digestion of Municipal Solid Waste. in Palmisano, A.C. and Barlaz, M.A. eds Microbiology of Solid Waste. CrC Press, Inc., Boca Raton, FL., 71-113

[17] Dhoble, A.S., Pullammanappallil, P. 2014. Design and operation of an anaerobic digester for waste management and fuel generation during long term lunar mission. Advances is Space Research 54: 1502 - 1512

[18] Termorshuizen, A.J., et al. 2003. Survival of human and plant pathogens during anaerobic mesophilic digestion of vegetable, fruit, and garden waste. European Journal of Soil Biology 39: 165-171.

[19] Clarke and Humphreys. 2006. Toxic factors in pea haulm silage effluent: The factor affecting germination and growth in plants. Journal of the Science of Food and Agriculture. Vol. 21 Issue 5. Pp.225-227. 2006.

14 ${ }^{\text {th }}$ LACCEI International Multi-Conference for Engineering, Education, and Technology: "Engineering Innovations for 